Syntax Literate : Jurnal Ilmiah Indonesia p-ISSN: 2541-0849 e-ISSN : 2548-1398

Vol. 4, No. 9 September 2019

\title{
IMPLEMENTASI REGULASI PELAYANAN MEDIS BAGI MAHASISWA KEDOKTERAN DI RUMAH SAKIT WALED KABUPATEN CIREBON
}

\section{Yandri Naldi}

Fakultas Kedokteran Universitas Swadaya Gunung Jati (UNSWAGATI) Cirebon

Email: Yandrinaldi2@gmail.com

\begin{abstract}
Abstrak
Tujuan dari penelitian ini untuk menganalisis implementasi regulasi pelayanan medis bagi mahasiswa kedokteran di Rumah Sakit Pendidikan, Untuk menganalisis implementasi regulasi pelayanan medis bagi mahasiswa di Rumah Sakit Umum Daerah Waled kabupaten Cirebon, Menganalisis kendala dan memberikan solusi dalam implementasi pelayanan medis bagi mahasiswa kedokteran. Penelitian ini merupakan penelitian kualitatif dengan metodologi deskriptif, penulis melakukan studi dokumentasi untuk mengkaji pelaksanaan regulasi pelayanan medis di Rumah Sakit Pendidikan Waled tahun Oktober 2011 s/d April 2012. Metode pengumpulan data dengan cara menggali peraturan perundang-undangan yang berlaku dan peraturan yang ada di Rumah Sakit Waled. Tehnik sampling yang digunakan menggunakan metode snowball. Data diambil dari data primer yang diperoleh dari managemen RS Waled, dan data sekunder dari peraturan perundang-undangan yang berlaku. Analisa data kualitatif dengan metode pendekatan yuridis normative. Aspek yuridis pelayanan medis tertuang pada (R. Indonesia, 2003),(Nasional, 2005). Aspek kompetensi pelayanan kesehatan bagi mahasiswa kedokteran tertuang dalam buku Standar Rumah Sakit Pendidikan Departemen Kesehatan, MOU RS Waled dan FK Unswagati, log book mahasiswa kedokteran di tiap SMF dan buku panduan praktek belajar lapangan/kepaniteraan yang dikeluarkan oleh Rumah Sakit Waled.
\end{abstract}

Kata kunci: Regulasi, pelayanan medis, mahasiwa kedokteran, Rumah Sakit Pendidikan, Rumah Sakit Waled.

\section{Pendahuluan}

Pelayanan kesehatan pada dasarnya bertujuan untuk meningkatkan mutu kesehatan bagi seluruh masyarakat. Dokter sebagai salah satu komponen utama pemberi pelayanan kesehatan masyarakat mempunyai peran yang sangat penting dan terkait secara langsung dengan proses pelayanan kesehatan dan mutu pelayanan yang diberikan. Ilmu pengetahuan, keterampilan, sikap dan perilaku sebagai kompetensi yang didapat selama pendidikan kedokteran merupakan landasan utama bagi dokter untuk dapat melakukan tindakan pelayanan kesehatan. 
Terjadi asumsi umum pada ruang publik bahwa pelayanan rumah sakit pemerintah seringkali mengalami kekecewaan demi kekecewaan begitupun di rumah sakit swasta tertentu dan isu itu telah merambah pada dimensi kesan personal atas pelayanan yang belum puas tadi. Hal ini tercermin dari banyaknya keluhan dari masyarakat misalnya tentang lamanya penyelesaian penangannan pasien terlebih jika jatuh pada hari libur, dan lambannya respon pegawai terhadap pasien. Lambannya pelayanan kesehatan telah mengakibatkan terhambatnya kepercayaan publik akan kualitas institusi kesehatan sebagai ruang harapan.(Pujiastuti, 2017)

Dari (R. Indonesia, 2004) ketentuan Standar Pendidikan Kedokteran dinyatakan bahwa setelah mahasiswa kedokteran lulus tahap sarjana mereka harus melalui tahap profesi dokter, pada tahap ini mereka magang atau bertugas di Rumah Sakit Pendidikan atau Puskesmas yang harus mereka tempati untuk mendapatkan gelar profesi dokter.

Dari Setiap orang dilarang menggunakan identitas berupa gelar atau bentuk lain yang menimbulkan kesan bagi masyarakat seolah-olah yang bersangkutan adalah dokter atau dokter gigi yang telah memiliki surat tanda registrasi dan atau surat izin praktik. Banyak dari ahli hukum yang menafsirkan ayat ini bahwa selain dokter atau dokter gigi tidak boleh melakukan pelayanan medis kepada pasien, dalam hal ini termasuk juga mahasiswa kedokteran, mereka tidak boleh melakukan pelayanan langsung kepada pasien, mereka hanya bisa melihat dokter Rumah Sakit atau Puskesmas yang melakukan pelayanan kesehatan kepada pasien. Sedangkan selama ini yang berlaku adalah mahasiswa kedokteran melakukan pelayanan kesehatan kepada pasien. Dari keterangan diatas maka peneliti akan melakukan penelitian untuk menilai Implementasi Regulasi pelayanan medis bagi mahasiswa kedokteran di Rumah Sakit Waled kabupaten Cirebon.

Tujuan penelitian yang diharapkan dalam penelitian ini adalah : 1) Mencari data tentang regulasi hukum pelayanan medis mahasiswa kedokteran di Rumah Sakit Pendidikan. 2) Mencari data tentang regulasi pelayanan medis mahasiswa kedokteran di Rumah sakit Waled Cirebon. 3) Mencari kendala dan solusi dalam pelayanan medis bagi mahasiswa kedokteran di Rumah Sakit Waled kabupaten Cirebon.

Adapun Manfaat yang diharapkan dari penelitian ini adalah sebagai berikut : 1) Untuk masukan dalam rangka regulasi hukum terhadap pelayanan kesehatan bagi mahasiswa kedokteran di Rumah Sakit Pendidikan. 2) Untuk mencari kendala dan solusi 
dalam implemengtasi regulasi pelayanan medis bagi mahasiswa di RS Pendidikan. 3) Untuk menambah wawasan ilmu pengetahuan hukum kesehatan khususnya dalam bidang pendidikan kedokteran.

\section{Metode Penelitian}

Dalam pelaksanaan penelitian ini penulis menggunakan metodologi penelitian kualitatif deskriptif dengan pendekatan yuridis normatif.. Penelitian ini berobjekan hukum normatif berupa asas-asas hukum, sistem hukum, taraf sinkronisasi vertikal dan horisontal. Jenis penelitian yang digunakan adalah penelitian deskriptif analitis, dengan pendekatan studi dokumentasi yaitu mengkaji dokumentasi yang dimiliki Rumah sakit pendidikan terhadap pelaksanaan pelayanan medis mahasiswa kedokteran di Rumah Sakit Pendidikan. Penelitian ini dilaksanakan di Rumah Sakit Umum Daerah Waled Kabupaten Cirebon. Pelaksanaan penelitian direncanakan pada bulan Oktober 2011 sampai dengan April 2012, dengan survei pendahuluan dilakukan pada bulan Juli 2011, penyusunan proposal bulan Oktober 2012, pengumpulan data dilakukan pada bulan November 2011 s/d Januari 2012. Serta pengolahan dan analisis data pada bulan Februari s/d Maret 2012. Objek penelitian ini adalah pihak managemen Rumah sakit Umum Daerah Waled Cirebon. Data penelitian ini berupa data primer dan data sekunder. Data primer didapatkan dari informan kunci dan dikembangkan dengan metode snow ball hingga diperoleh informasi yang mendalam. Informan kunci yang pertama kali ditemui yaitu Kepala Badan koordinasi pendidikan RSUD Waled, dipilih berdasarkan tugas pokok dan fungsinya sebagai orang yang bertanggungjawab dalam pelayanan medis mahasiswa kedokteran di Rumah Sakit. Informan berikutnya didapat dari rekomendasi informan pertama. Kriteria memilih informan: 1). Subjek yang menghayati (enkulturasi) cukup dengan lingkungan-nya; 2). Subjek yang masih terlibat; 3). Cukup waktu dan kesempatan. Data sekunder adalah data yang diperoleh dari sumber kepustakaan yang mencakup dokumen, buku, perundang-u ndangan, laporan penelitian dan lain-lain.

Pengumpulan dan penelitian dilakukan dengan teknik wawancara mendalam (deep interview), bentuk wawancara berupa: 1) Wawancara terstruktur, peneliti telah mempersiapkan permasalahan dan beberapa pertanyaan yang akan diajukan kepada informan kunci maupun informan lainnya (Kepala Badan koordinasi pendidikan, kepala 
ruangan, dokter, dll). 2) Wawancara tak berstruktur, pada jenis wawancara ini peneliti mengajukan pertanyaan-pertanyaan ke informan secara lebih bebas dan leluasa, tanpa terikat oleh susunan pertanyaan yang telah dipersiapkan sebelumnya. 3) Studi kepustakaan, peneliti melakukan studi kepustakaan terhadap dokumen, hasil penelitian, buku-buku, artikel dan bahan-bahan pustaka yang berkaitan dengan penelitian. Selain itu pengumpulan data juga dilakukan dengan cara peneliti sebagai partisipasi (observer as participant) yakni peneliti menempatkan dirinya sebagai partisipan yang mengikuti dan mengalami keseluruhan proses yang juga dilakukan oleh informan. Peneliti mengikuti kegiatan di ruang Unit Gawat Darurat (UGD), ruang perawatan, ICU dan lainnya. Dengan metode ini peneliti dapat menguji data hasil wawancara akurat sesuai dengan fakta di lapangan (triangulasi). Selanjutnya karena penelitian kualitatif bertolak dari asumsi tentang realitas sosial yang bersifat unik, kompleks dan ganda, sehingga akan terdapat regularitas atau pola tertentu, tetapi penuh dengan variasi, oleh karenanya kegiatan penelitian harus sengaja memburu informasi seluas mungkin ke arah keragaman atau variasi yang ada.

Metode analisis yang digunakan metode deskriptif yuridis normative, dengan tujuan untuk membuat deskripsi, gambaran secara sistematis, faktual dan akurat mengenai fakta-fakta, sifat-sifat serta hubungan antar fenomena yang diselidiki. Metode deskriptif adalah metode penelitian untuk membuat gambaran mengenai situasi atau kejadian, sehingga metode ini berkehendak mengadakan akumulasi data dasar belaka.

Selanjutnya, analisis data dalam penelitian kualitatif dengan berdasarkan pada model interaktif yaitu peneliti melakukan kegiatan yang berulang-ulang, berlanjut terus menerus, yang bergerak dalam empat siklus kegiatan secara bolak-balik, yaitu koleksi data, reduksi data, display (penyajian) data dan verifikasi data atau penarikan kesimpulan. Kegiatan yang berbentuk siklus ini diharapkan akan menghasilkan data yang representatif dan relevan dengan masalah yang diteliti. Data yang diperoleh setelah melalui teknik pengecekan validitas data sehingga terjamin validitasnya, disajikan dalam bentuk uraian yang sistematis, kemudian direduksi sedemikian rupa sampai ditarik suatu kesimpulan/verifikasi. 


\section{Hasil Dan Pembahasan}

Tanggal 22 Oktober 2011 RSUD Waled mengadakan kerjasama dengan Fakultas Kedokteran Universitas swadaya Gunung jati Cirebon. Kerjasama ini ditandatangai oleh dr. Affandi, SpA sebagai Dekan Fakultas Kedokteran Universitas Swadya Gunung Jati dengan dr. J. Suwanta sebagai Direktur Rumah Sakit Umum Daerah Waled. Kerjasama ini berfungsi untuk melaksanakan pelayanan kesehatan pada masyarakat, tempat pendidikan, pelatihan, penelitian dan pengembangan sehingga semua potensi yang ada dapat berdaya guna dan berhasil guna serta untuk meningkatkan kualitas pelayanan kesehatan dan pendidikan kesehatan.

1) Aspek yuridis kompetensi pelayanan medis mahasiswwa kedokteran di Rumah Sakit Pendidikan

Berdasarkan hasil kajian yang penulis dapatkan dari beberapa perundangundangan dan peraturan pemerintah yang penulis dapatkan diperoleh hasil sebagai berikut :

a. (R. Indonesia, 2004) disebutkan : Pendidikan adalah usaha sadar dan terencana untuk mewujudkan suasana belajar dan proses pembelajaran agar peserta didik secara aktif mengembangkan potensi dirinya untuk memiliki kekuatan spiritual keagamaan, pengendalian diri, kepribadian, kecerdasan, akhlak mulia, serta keterampilan yang diperlukan dirinya, masyarakat, bangsa dan negara.

b. (NIM, 2015) mengenai standar kompetensi lulusan, pada pasal 26 ayat 4 di sebutkan : Standar kompetensi lulusan pada jenjang pendidikan tinggi bertujuan untuk mempersiapkan peserta didik menjadi anggota masyarakat yang berakhlak mulia, memiliki pengetahuan, keterampilan, kemandirian dan sikap untuk menentukan, mengembangkan serta menerapkan ilmu, teknologi dan seni yang bermanfaat bagi kemanusiaan. pendidikan profesional adalah pendidikan tinggi yang diarahkan terutama pada kesiapan penerapan keahlian tertentu. Tujuan pendidikan tinggi adalah a). menyiapkan peserta didik menjadi anggota masyarakat yang memiliki kemampuan akademik dan/atau profesional yang dapat menerapkan, mengembangkan dan/atau memperkaya khasanah ilmu pengetahuan, teknologi dan/atau kesenian; b). mengembangkan dan menyebarluaskan ilmu pengetahuan, teknologi dan/atau kesenian serta mengupayakan penggunaannya untuk meningkatkan taraf kehidupan masyarakat dan memperkaya kebudayaan 
nasional.

c. (K. K. Indonesia, 2006) dinyatakan bahwa Struktur kurikulum pendidikan kedokteran terdiri dari dua tahap, yaitu tahap sarjana kedokteran dan tahap profesi dokter. Tahap sarjana kedokteran dilakukan minimal 7 semester (112 minggu atau minimal 4480 jam atau minimal 144 SKS) dan diakhiri dengan gelar Sarjana Kedokteran (S.Ked). Tahap profesi dokter dilakukan minimal 3 semester (minimal 72 minggu atau minimal 2880 jam) di Rumah Sakit Pendidikan dan wahana pendidikan lain, serta diakhiri dengan gelar Dokter.

2) Aspek kompetensi pelayanan medis mahasiswa kedokteran di Rumah Sakit Waled

Regulasi pelayanan medis bagi mahasiswa kedokteran di Rumah Sakit yang akan peneliti kaji adalah Berdasarkan buku Standar Rumah Sakit Pendidikan yang dikeluarkan oleh (Efendi \& Makhfudli, 2009) mengenai Standar Rumah Sakit Pendidikan Utama diantaranya adalah :

a. Koordinasi pendidikan profesi kedokteran

Untuk kelancaran proses manajemen dan administrasi pendidikan harus mempunyai Badan Koordinasi Pendidikan, yang terdiri atas unsur Rumah sakit pendidikan dan Institusi Pendidikan Kedokteran yang memiliki uraian tugas dan fungsi yang jelas.

Dalam perjanjian kerjasama antara Fakultas Kedokteran Unswagati dengan Rumah Sakit Waled pada Bab IV tentang organisasi, Pasal 4 menyebutkan 1) PIHAK PERTAMA adalah Rumah Sakit yang dipakai sebagai Rumah Sakit Pendidikan Utama PIHAK KEDUA. 2) PIHAK PERTAMA adalah Organisasi Perangkat Daerah di lingkungan Pemerintah Kabupaten Cirebon, berada di bawah dan bertanggung jawab langsung kepada Bupati Cirebon dan dipimpin oleh seorang Direktur. 3) PIHAK KEDUA adalah Unit Organik di bawah Univesitas Swadaya Gunung Jati (Unswagati) Cirebon yang bertanggung jawab kepada Rektor dan dipimpin oleh seorang Dekan. 4) Perjanjian Kerjasama ini meliputi kawasan kerjasama yang disepakati oleh PARA PIHAK dengan melibatkan semua satuan organisasi di bawahnya dalam menunjang dan melaksanakan fungsi masing-masing. 5) Dalam melaksanakan tugas dan fungsi PARA PIHAK serta segala sesuatu yang berkaitan dengan Perjanjian Kerjasama 
ini dilaksanakan oleh BAKORDIK. 6) Staf Medis Fungsional yang selanjutnya disebut SMF adalah kelompok dokter spesialis yang bertugas/bekerja di Instalasi dalam jabatan fungsionalnya sebagai pendidik dan pembimbing pembelajaran klinik.

b. Kebijakan penyelenggaraan pendidikan

Rumah sakit Pendidikan memiliki kebijakan, peraturan dan ketetapan tertulis mengenai pendidikan sehingga dapat menjamin terselenggaranya pendidikan yang berkualitas tinggi.

Dalam Perjanjian kerjasama antara Fakultas Kedokteran dengan RSUD Waled pasal 15 mengenai Pendidikan ayat satu disebutkan penyelenggaraan pendidikan mahasiswa pihak kedua diatur dan diawasi pelaksanaannya berdasarkan ketentuan bersama antara Dekan dan Direktur yang akan diatur dalam petunjuk pelaksanaan, ayat 2 pihak kedua berwenang menetapkan persyaratan, cara dan metode pendidikan mahasiswa pihak kedua dengan mempertimbangkan masukan pihak pertama. Ayat 3 Biaya yang timbul akibat proses pelaksanaan pendidikan mahasiswa PIHAK KEDUA di PIHAK PERTAMA menjadi tanggung jawab PIHAK KEDUA sebagaimana tercantum dalam Lampiran 1 Perjanjian ini. Ayat 4 Dekan berwenang/bertanggung jawab atas : a) Semua kebijaksanaan yang ditetapkan untuk pendidikan. b) Semua pelaksanaan pendidikan dan penelitian sepanjang melibatkan kedua belah pihak dalam hal-hal khusus yang membutuhkan sarana dan tenaga yang mempunyai dampak terhadap pelayanan dan anggaran harus dikonsultasikan terlebih dahulu dengan PIHAK PERTAMA. Ayat 5 PIHAK PERTAMA mengatur penyediaan kasus/penderita, rekam medik untuk kepentingan pendidikan dan penelitian yang dilakukan oleh PIHAK KEDUA dan tetap memegang teguh etika kedokteran dan etika Rumah Sakit. Ayat 6 Dalam pelaksanaan P3D harus mengacu kepada pedoman akademis dan aspek medicolegal yang telah disetujui oleh PARA PIHAK. Ayat 7 Rekam Medik adalah milik PIHAK PERTAMA, penggunaan informasi rekam medik untuk kepentingan diluar pendidikan harus mendapat ijin tertulis dari PIHAK PERTAMA.

Dalam buku pedoman kepaniteraan Klinik yang diterbitkan oleh Rumah Sakit disebutkan untuk mengikuti program kepaniteraan klinik harus memenuhi 
persyaratan akademik dan administratif yakni lulus dari Program Pendidikan Sarjana Kedokteran dan telah mengikuti Program Kepaniteraan Umum. Mahasiswa akan dibagi-bagi di bagian SMF (staf Medik Fungsional) misalkan Bagian Penyakit Dalam, kesehatan anak, Bedah, Kebidanan \& Kandungan, penyakit syaraf, Penyakit THT, penyakit mata, radiologi, anestesi, dan lain-lain. Waktu kepaniteraan ditetapkan oleh Rumah Sakit, kegiatan dan pelaksanaan pelayanan medis oleh mahasiswa kedokteran ditentukan oleh masing-masing bagian tersebut, hal-hal yang boleh dilakukan dan tidak boleh dilakukan ditetapkan oleh bagian masing-masing. Bentuk pembelajaran mahasiswa terdiri dari : 1) Sesi Klinik/Komunitas : diskusi ilmiah tentang satu topik yang berhubungan dengan pasien BST (Bed Side Teaching). 2) Sesi Laporan Kasus : diskusi ilmiah dalam bentuk presentasi kasus setelah dilakukan pemeriksaan pasien sewaktu melakukan kegiatan Bed Side Teaching. 3) Sesi Temu Ahli/Pakar : forum diskusi ilmiah yang menghadirkan para ahli/pakar dari setiap departemen yang dapat memberikan kesempatan kepada mahasiswa untuk mendiskusikan isu-isu tentang pasien yang belum difahami. Kebijakan pedoman pelaksanaan kepaniteraan klinik ini disosialisasi kepada para mahasiswa, kepala bagian, kepala ruangan dan dokter-dokter yang bertugas di Rumah Sakit Waled. Selain itu Mahasiswa juga diberikan log book untuk memantau dan mengevaluasi kegiatan yang mereka lakukan di tiap bagian.

Pada perjanjian kerjasama antara fakultas kedokteran dengan Rumah Sakit Waled dan pedoman kepaniteraan klinik belum disebutkan adanya daya tampung peserta yang didasarkan rasio pendidik dengan peserta didik maksimal $1: 5$, rasio daya tampung tersebut penting mengingat ini merupakan peraturan dari Konsil Kedokteran Indonesia mengenai pelaksanaan kegiatan kepaniteraan klinik di Rumah Sakit, dengan rasio tersebut pembimbing di tiap bagian lebih mudah mengawasi pelaksanaan mahasiswa kedokteran dalam kepaniteraan kliniknya.

Dalam perjanjian kerjasama disebutkan juga mengenai sistem penyelenggaraan pendidikan, penelitian dan pelayanan beserta berbagai unsur penunjangnya yang ditetapkan dalam pasal 14 hingga pasal 17. 
c. Sarana dan prasarana yang menunjang kegiatan pelayanan kepaniteraan mahasiswa

Luas total luas lahan Rumah sakit Waled Cirebon sebesar $34.750 \mathrm{~m} 2$, sedangkan luas bagunan yang dimiliki sebanyak $15.300 \mathrm{~m} 2$, daerah resapan \& ruang terbuka hijau sebanyak $5.212,5 \mathrm{~m} 2$, dan sisa lahan yang tersedia sebanyak 14.237,5 m2. Sedangkan asrama untuk mahasiswa yang akan melakukan kepaniteraan klinik di RSUD Waled memiliki daya tampung 25 beds dengan total luas asrama sebesar $508.5 \mathrm{~m} 2$, asrama mahasiswa terdiri dari dua lantai. Selain itu asrama mahasiswa memiliki ruang kantor, ruang tamu, ruang seterika, dapur, gudang, ruang makan, kamar mandi luar dan dalam, ruang penjaga dan ruang diskusi.

Rumah Sakit Waled sudah banyak memiliki bagian-bagian poliklinik diantaranya : Poliklinik Penyakit Dalam, Bedah, Kebidanan, Orthopedi, Bedah syaraf, Kesehatan Anak, Neurorolgi, Jiwa, THT, Mata dan Radiologi. Rumah Sakit waled juga sudah memilki bagian perawatan untuk masing-masing spesialis diantaranya ruang perawatan Penyakit Dalam, Bedah, Kebidanan, Orthopedi, Bedah syaraf, Kesehatan Anak, Neurologi, THT dan mata. Beberapa spesialis terdapat dalam satu ruang perawatan misalkan ruang perawatan bedah, ruang perawatan ortopaedi dan ruang perawatan bedah saraf menjadi satu tempat. Rumah Sakit Waled juga memiliki peralatan yang canggih dan memadai, diantaranya memilki peralatan bedah alat $\mathrm{C}$-arm untuk pembedahan ortopaedi, alat vitrektomi slit lamp, laser dan lensa eiboos untuk bedah mata, alat endoskopi, gastroskopi dan colonoskopi untuk pemeriksaan organ-organ dalam, alat microskop surgery untuk bedah syaraf dan bedah mata. Pelayanan perinatologi RSUD Waled, berdasarkan penilaian dari RS Hasan sadikin Bandung dari aspek ketenagaan, sarana prasarana, mampu menangani kasus severity level III. RSUD Waled juga sudah memilki NICU (Neonatal Intensive care Unit). Selain itu juga sudah memiliki Ruang bedah sentral yang sudah distandarisasi, layanan laboratorium dan radiologi yang lengkap.

d. Sumber Daya Manusia dalam kepaniteraan klinik

Rumah Sakit Waled memiliki berbagai macam dokter spesialis diantaranya adalah dokter spesialis Penyakit Dalam (2 orang), dokter spesialis 
Bedah umum (1 orang), dokter spesialis bedah ortopedi (1 orang), dokter spesialis bedah syaraf (1 orang), dokter spesialis Kebidanan dan penyakit kandungan (4 orang), dokter spesialis Kesehatan Anak (2 orang), dokter spesialis Penyakit Syaraf (1 orang), dokter spesialis Kedokteran Jiwa (1 orang), dokter spesialis Penyakit THT (1 orang), dokter spesialis Penyakit Mata (2 orang), dokter spesialis Radiologi (2 orang), dokter spesialis Anestesi (1 orang). Selain dokter spesialis Rumah sakit Waled juga banyak didukung oleh dokter umum sebanyak kurang lebih 20 dokter umum, dokter umum tersebut juga dapat bertindak sebagai pembimbing mahasiswa kedokteran di Rumah Sakit waled.

\section{Kesimpulan}

Kesimpulan yang didapatkan peneliti pada penelitian ini adalah :

1. Pelaksanaan pelayanan medis mahasiswa kedokteran di Rumah Sakit Pendidikan sudah sesuai dengan ketentuan perundang-undangan.

2. Pelaksanaan pelayanan medis mahasiswa kedokteran di Rumah Sakit Waled sudah memadai, yakni dengan adanya peraturan-peraturan internal dalam Rumah Sakit Waled, mulai dari perjanjian kerjasama dengan Fakultas Kedokteran Unswagati, buku pedoman pelaksanaan kepaniteraan hingga log book mahasiswa, selain itu fasilitas sarana prasarana, pelayanan poliklinik sudah lengkap.

3. Kendala di Rumah Sakit Waled sebagai Rumah Sakit Pendidikan diantaranya adalah kurangnya jumlah dokter spesialis dan waktu jam kerja pelayanan medis spesialis. 


\section{BIBLIOGRAFI}

Efendi, F., \& Makhfudli, M. (2009). Keperawatan Kesehatan Komunitas: teori dan praktik dalam keperawatan. Salemba Medika.

Indonesia, K. K. (2006). Standar kompetensi dokter. Jakarta: Konsil Kedokteran Indonesia.

Indonesia, R. (2003). Undang-undang Republik Indonesia nomor 20 tahun 2003 tentang sistem pendidikan nasional. Jakarta: Pemerintah Republik Indonesia.

Indonesia, R. (2004). Undang-Undang Republik Indonesia Nomor 32 Tahun 2004 Tentang Pemerintahan Daerah. Jakarta (ID): RI.

Nasional, D. P. (2005). Peraturan Pemerintah Nomor 19 Tahun 2005. Tentang Standar Nasional Pendidikan.

NIM, E. F. A. (2015). Implementasi Peraturan Pemerintah No. 19 Tahun 2005 Tentang Standar Nasional Pendidikan di Sekolah Dasar Negeri No. 04 Pengadang. PUBLIKA-Jurnal Ilmu Administrasi Negara, 4(3).

Pujiastuti, E. (2017). Hubungan Antara Kompetensi Profesional Tenaga Medis, Budaya Kerja Dan Gaya Kepemimpinan Dengan Mutu Pelayanan Pasien Rawat Inap Di Rumah Sakit Waled Kab. Cirebon. Syntax Literate; Jurnal Ilmiah Indonesia, 2(4), 34-65. 